\title{
Effect of Mo Concentration and Aging Time on the Magnetic and Mechanical Hardness of Fe-xMo-5Ni-0.05C Alloys (x = 5, 8, 11 and 15 wt. (\%))
}

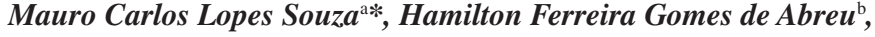 \\ Sérgio Souto Maior Tavares ${ }^{c}$, Manoel Antonio da Fonseca Costa Filho \\ ${ }^{a}$ Departamento de Engenharia Mecânica, Faculdade de Engenharia - FEN, \\ Universidade do Estado do Rio de Janeiro - UERJ \\ 20940-200, Rio de Janeiro - RJ, Brazil \\ ${ }^{\mathrm{b}}$ Departamento de Engenharia Metalúrgica e Materiais, \\ Universidade Federal do Ceará - UFC \\ 60020-181, Fortaleza-CE, Brazil \\ 'Departamento de Engenharia Mecânica, \\ Universidade Federal Fluminense - UFF \\ 24210-240, Niteroi - RJ, Brazil
}

Received: May 4, 2009; Revised: September 24, 2009

\begin{abstract}
Changes to the microestructure during thermal aging treatment at $610^{\circ} \mathrm{C}$ in $\mathrm{Fe}-\mathrm{xMo}-5 \mathrm{Ni}-0.05 \mathrm{C}$ alloys were studied for different aging times with different Mo concentrations. The heat treatment at $610{ }^{\circ} \mathrm{C}$ induces carbide precipitation into the metallic matrix near $\mathrm{Fe}_{2} \mathrm{Mo}$ phase. The X-ray diffraction studies revealed a more intense precipitation of $\alpha$-FeMo, $\mathrm{Fe}_{3} \mathrm{Mo}, \mathrm{R}\left(\mathrm{Fe}_{63} \mathrm{Mo}_{37}\right)$ phases and $\mathrm{MoC}, \mathrm{Fe}_{2} \mathrm{MoC}$ carbides for the alloys containing 15 and $11 \%$ Mo, respectively. This work shows that hardness and coercive force changes are function of the molybdenum content and aging time variation. Vickers hardness and coercive force both increase with the increase of molybdenum content and reach maximum values at 4 and $1 \mathrm{~h}$ of aging, respectively.
\end{abstract}

Keywords: Fe-Mo-Ni-C alloys, magnetic aging, mechanical aging, magnetic hardness

\section{Introduction}

The alloys based on the Fe-Mo-Ni-C system used for permanent magnets may achieve similar magnetic properties to Vicalloy II $(\mathrm{FeCoV})$ and other Fe-Co alloys, but are advantageous since they do not have cobalt, which is a strategic and expensive alloying element ${ }^{1}$. These alloys are ductile, and tolerate cold deformations larger than $99 \%$ without intermediary thermal treatment ${ }^{2}$. The coercive force of these alloys varies between 17,600 to $36,700 \mathrm{~A} / \mathrm{m}$ depending on factors as cold deformation, molybdenum content, and heat treatment parameters.

The permanent magnet can be described using four properties: Saturation magnetization $\left(\mathrm{B}_{\mathrm{c}}\right)$; Remanence $\left(\mathrm{B}_{\mathrm{r}}\right)$; Coercive force $\left(\mathrm{H}_{\mathrm{c}}\right)$; Energetic product $\left(\mathrm{BH}_{\max }\right)$. Among these parameters, only saturation magnetization is not dependent upon the material microstructure. One of the mechanisms of actuating magnetic hardness is the barrier created by carbide precipitation that restricts the movement of the magnetic domains walls. The carbide precipitation may also acts as a barrier against dislocation motion, and influences the mechanical properties of the materials such as hardness, yield and strength limits $^{3}$.

The Mo addition increases the lattice parameter of the $\alpha$-Fe. Adding Mo to $\mathrm{Fe}$ also increases its hardness, this effect being surpassed only by $\mathrm{Cr}, \mathrm{Co}, \mathrm{W}$ and $\mathrm{V}$. Mo is also responsible for the increase of crystallization temperature of the ferrite. Fe-Mo alloys containing Mo quantities higher than $6 \mathrm{wt}$. (\%) can be hardened by precipitation.
The magnetic and mechanical hardening of the Fe-Mo and Fe-Mo-Ni alloys are attributed to $\lambda\left(\mathrm{Fe}_{2} \mathrm{Mo}\right)^{[4]}$ and/or $\mu\left(\mathrm{Fe}_{7} \mathrm{Mo}_{6}\right)^{[5]}$ precipitation during the aging. In the Fe-20Mo-5Ni-0.05C alloys, $\mathrm{MC}_{6}(\mathrm{M}=\mathrm{Fe}, \mathrm{Mo})$ precipitates are also present and may contribute to the increase of coercivity and mechanical hardness ${ }^{6,7}$.

Table 1 shows hardness values for Fe-Mo alloys solution treated at $1400{ }^{\circ} \mathrm{C}$, and aged aging at $620^{\circ} \mathrm{C}$ for 20 hours ${ }^{8}$.

$\mathrm{X}$-ray diffraction studies ${ }^{9}$ for $\mathrm{Fe}-\mathrm{Mo}-\mathrm{Ni}-\mathrm{C}$ alloys containing 5, 8 , 11 and 15 wt. (\%) show a more intense precipitation of the $\alpha \mathrm{FeMo}$, $\mathrm{Fe}_{3} \mathrm{Mo}, \mathrm{R}\left(\mathrm{Fe}_{63} \mathrm{Mo}_{37}\right)$ phases, and $\mathrm{MoC}, \mathrm{Fe}_{2} \mathrm{MoC}$ carbides for alloys containing 15 and $11 \%$ Mo, respectively. This clearly shows the influence of precipitates on the magnetic properties of $\mathrm{Fe}-\mathrm{Mo}-\mathrm{Ni}-\mathrm{C}$ alloys. However, recent studies on thermal magnetic analyses of Fe-Mo-Ni-C highlighted the influence of the Mo on the Curie temperature. The curves demonstrate that the transition temperature increases with decreasing the of Mo content ${ }^{10}$.

In this work the coercive force and mechanical hardness values of Fe-Mo-Ni-C alloys were compared for alloys with Mo contents 5, 8,11 and 15 wt. (\%) heat treated by aging at 610 and $650{ }^{\circ} \mathrm{C}$

\section{Experimental}

The alloys Fe-xMo5Ni0.05C ( $\mathrm{x}=5,8,11$ and 15 wt. (\%)) were initially obtained from high purity powder of the constituent elements 
Table 1. Values of hardness for alloys with different concentrations of Mo.

\begin{tabular}{ccc}
\hline & Rockwell C Hardness & \\
\hline Molybdenum content $(\%)$ & Solution treated at $1400{ }^{\circ} \mathrm{C}$ & Aged 20 hours at $620^{\circ} \mathrm{C}$ \\
\hline 10 & 7 & 25 \\
15 & 10 & 35 \\
20 & 23 & 51 \\
22 & 26 & 59 \\
25 & 35 & 63 \\
30 & 40 & 65 \\
\hline
\end{tabular}

Sykes $(1938)^{[8]}$.

Table 2. Chemical composition of the melted ingots

\begin{tabular}{|c|c|c|c|c|c|c|c|c|}
\hline \multicolumn{9}{|c|}{ Composition $(\%)$} \\
\hline Alloy & $\mathrm{Fe}$ & Mo & $\mathrm{Ni}$ & $\mathrm{C}$ & $\mathrm{Mn}$ & $\mathrm{S}$ & $\mathrm{P}$ & $\mathrm{Si}$ \\
\hline Fe-5Mo-5Ni-0.05C & Bal. & 4.78 & 5.61 & 0.047 & 0.14 & 0.009 & 0.010 & 0.008 \\
\hline $\mathrm{Fe}-8 \mathrm{Mo}-5 \mathrm{Ni}-0.05 \mathrm{C}$ & Bal. & 7.67 & 5.42 & 0.046 & 0.16 & 0.011 & 0.012 & 0.010 \\
\hline Fe-11Mo-5Ni-0.05C & Bal. & 10.64 & 5.40 & 0.053 & 0.13 & 0.007 & 0.009 & 0.009 \\
\hline $\mathrm{Fe}-15 \mathrm{Mo}-5 \mathrm{Ni}-0.05 \mathrm{C}$ & Bal. & 14.75 & 4.92 & 0.055 & 0.16 & 0.008 & 0.009 & 0.010 \\
\hline
\end{tabular}

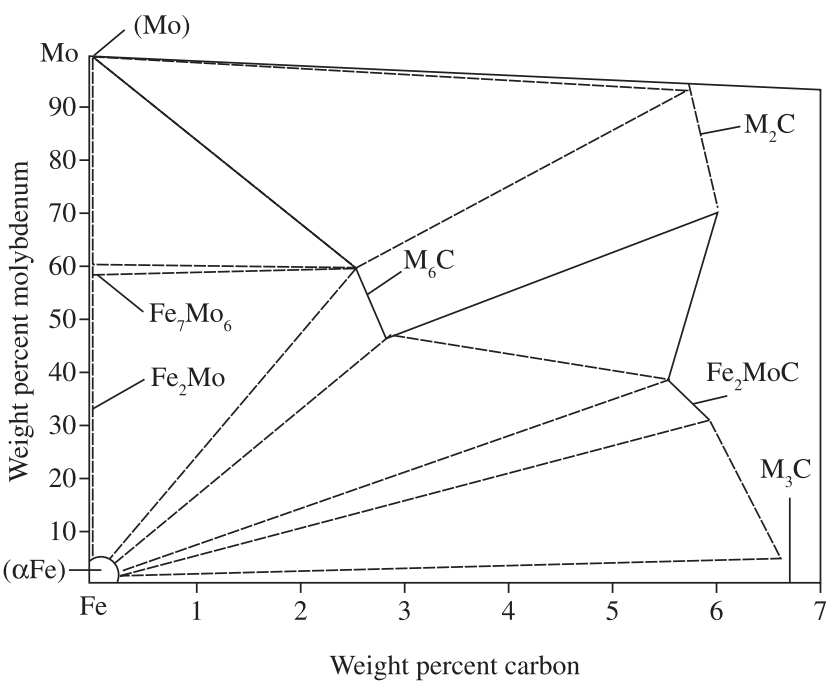

Figure 1. Isothermal section at $700{ }^{\circ} \mathrm{C}$ for the phase equilibrium diagram of Fe-Mo-C system.

melted in an arc furnace. The pieces were melted in an induction furnace under argon atmosphere in order to produce the ingots. Table 2 gives the chemical composition of the melted ingots.

The ingots were divided into slices that were soaked at $1250{ }^{\circ} \mathrm{C}$ for about 30 minutes and hot rolled for a reduction of $60 \%$ after which they were solution treated at $1200{ }^{\circ} \mathrm{C}$ and oil cooled.

After solution treatment $3 \mathrm{~mm}$ diameter thin discs were machined for the magnetic measurements. The final sample thickness varied between 0.05 and $0.12 \mathrm{~mm}$. These samples were aged at 610 and $650^{\circ} \mathrm{C}$ for several time intervals: 0, 15, 40, 60, 240, 600 and 1080 minutes and water cooled. After aging, all samples were cleaned and polished in order to remove the oxide layer.

The magnetic measurements were carried out in a vibrating sample magnetometer (VSM) EGG-PAR model 4500. The hardness tests were performed in a Vickers microhardner. The microstructure was analyzed by X-ray diffraction, using a Phillips ${ }^{\circledR}$ X-Pert difractometer using $\mathrm{K} \alpha-\mathrm{Cu}$.

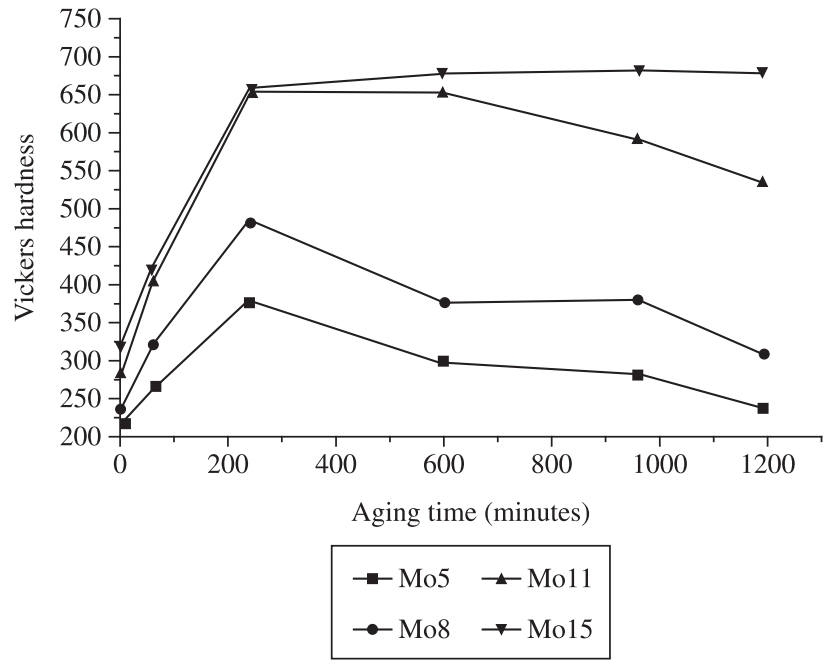

Figure 2. Variation of Vickers hardness as a function of the magnetic aging of Fe-Mo-Ni-C alloys containing different molybdenum concentrations.

\section{Results and Discussion}

Sato et al. ${ }^{11}$ studied the mechanism of precipitation of Fe-Mo-Ni alloys without carbon, and concluded that alloys containing less than $20 \%$ Mo and less than $5 \%$ Ni contained preferential regions in which platelet shapes were produced by nucleation and growth, and increased in number and size with the magnetic aging time. Magnetic hardness tests with Fe-Mo-Ni-C alloy containing $0.05 \% \mathrm{C}$ and $20 \%$ Mo, conducted by Tavares et al. ${ }^{12}$, revealed the presence of $\lambda$ phase $\left(\mathrm{Fe}_{2} \mathrm{Mo}\right)$ and $\mathrm{M}_{6} \mathrm{C}$. An analysis of the $\mathrm{Fe}-\mathrm{Mo}-\mathrm{C}$ equilibrium phase diagram ${ }^{13}$ in Figure 1 shows that in the isotherm at $700{ }^{\circ} \mathrm{C}$, increasig Mo results in an increase of the $\lambda$ phase $\left(\mathrm{Fe}_{2} \mathrm{Mo}\right)$ volume fraction and a reduction of $\mathrm{M}_{6} \mathrm{C}$ carbide. The likely explanation for the behavior of the magnetic and mechanical hardness curves obtained, is that the precipitation of $\mathrm{M}_{6} \mathrm{C}$ carbides takes place in the first step of heat treatment at $610^{\circ} \mathrm{C}$, which increases the magnetic and mechanic hardness. Maintaining the heat treatment, increases the number of 


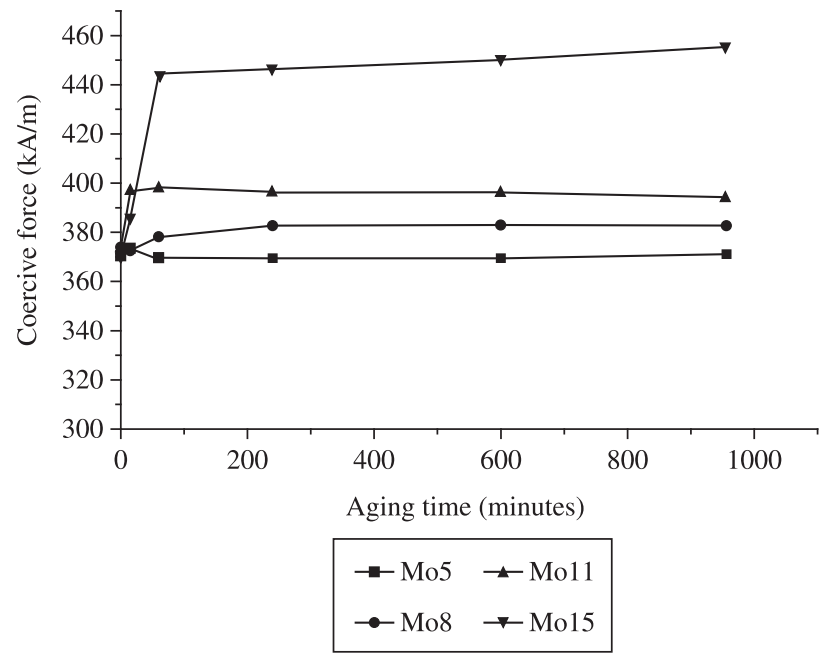

Figure 3. Coercive force vs. magnetic aging of Fe-Mo-Ni-C alloys, for different molybdenum concentrations.

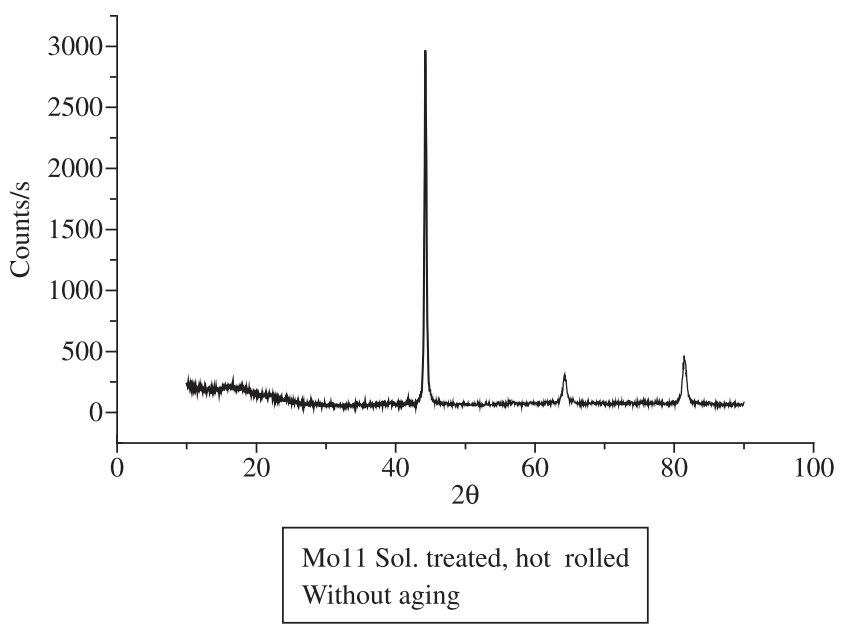

Figure 4. Diffractogram of alloy containing $11 \mathrm{wt}$. (\%) Mo, solution treated at $1250{ }^{\circ} \mathrm{C}$, after hot rolling, without aging.

blanks which reduces dislocation in spite of the precipitation of carbides and $\lambda$ phase $\left(\mathrm{Fe}_{2} \mathrm{Mo}\right)$. In $\mathrm{Fe}-\mathrm{Mo}-\mathrm{C}$ alloys containing more than 20 wt. (\%) Mo, the quantity of the $\lambda$ phase ( $\mathrm{Fe}_{2} \mathrm{Mo}$-fragile Laves phase and high hardness) is higher, reducing the mechanic hardness.

Souza ${ }^{9}$ demonstrated that the main process controlling the magnetic response is the precipitates barrier inhibiting the movement of the magnetic domain walls. These precipitates also interfere with the dislocation movement inside the material when submitted to deformation.

Figure 2 exhibits the variation in the Vickers hardness of Fe-Mo-Ni-C alloys containing different quantities of Mo as a function of the aging heat treatment time. For all samples, the Vickers hardness increases during the first 3 hours of aging. After this time, the alloy containing $15 \%$ of Mo exhibits different behavior than alloys with less Mo in the composition. The samples containing 5, 8 and $11 \%$ of Mo show a decrease in Vickers hardness with the increase of aging time, while the $15 \%$ Mo alloy has an approximately constant Vickers hardness.

The variation of the coercive force is also a function of the aging time. The behaviour of coercive force for the alloys studied is

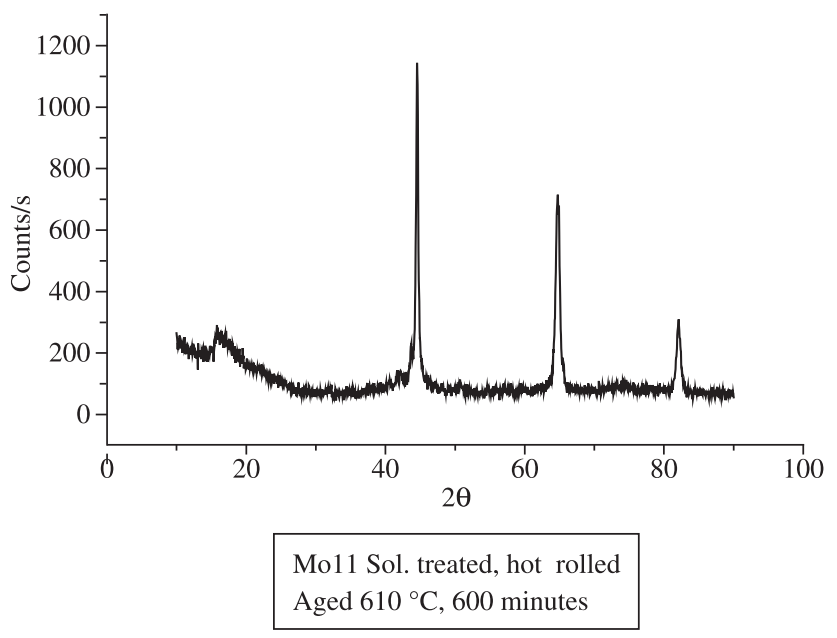

Figure 5. Diffractogram of alloy containing $11 \mathrm{wt}$. (\%) Mo, solution treated at $1250{ }^{\circ} \mathrm{C}$, after hot rolling, aged at $610{ }^{\circ} \mathrm{C}$ for 600 minutes.

Table 3. Precipitates identified by X-ray diffractometry for alloys containing $11 \% \mathrm{Mo}$, hot rolled, solution treated at $1200{ }^{\circ} \mathrm{C}$, without aging and aged at $610^{\circ} \mathrm{C}$ for 600 minutes, classified as high, middle or low.

\begin{tabular}{lcc}
\hline $\begin{array}{l}\text { Phases and } \\
\text { Compounds }\end{array}$ & $\begin{array}{c}\text { Without } \\
\text { aging }\end{array}$ & $\begin{array}{c}\text { Aged at } 610{ }^{\circ} \mathrm{C} \\
\text { for } 600 \mathrm{~min}\end{array}$ \\
$\lambda$ phase & low & high \\
$\mathrm{Fe}_{3} \mathrm{Mo}$ & low & middle \\
$\mathrm{R} \mathrm{phase}$ & middle & high \\
$\mathrm{Fe}_{0,54} \mathrm{Mo}_{0,73}$ & low & middle \\
$\mathrm{MoC}_{\alpha \mathrm{Co}} \mathrm{C}$ & middle & high \\
$\mathrm{Fe}_{2} \mathrm{MoC}$ & low & middle \\
$\mathrm{FeC}$ & middle & high \\
$\mathrm{Fe}_{2} \mathrm{C}$ & low & middle \\
$\mathrm{Fe}_{3} \mathrm{C}$ & low & middle \\
\hline
\end{tabular}

shown in Figure 3. The coercive force increases with the amount of Mo, however, a maximum value is reached at nearly 1 hour of heat treatment and then remains constant. This behavior is similar for all alloys, independently from the Mo content.

Souza et al. ${ }^{10}$ demonstrated the effect of performing a cold work step prior to aging on the coercive force of the $\mathrm{Fe}-15 \mathrm{Mo}-5 \mathrm{Ni}-0.05 \mathrm{C}$ alloy is very expressive. The coercive force decreases when the cold working step is done. This result is somewhat surprising, since the introduction of crystalline defects should increases the precipitation. Abreu et $\mathrm{al}^{2}$. found similar results for the $11 \% \mathrm{Mo}_{\text {alloy }}{ }^{14}$.

Figures 4 and 5 show diffractograms of the sample Fe11Mo5Ni0.05C for the following conditions: hot rolled, solution treated, without aging and hot rolled, solution treated, aged at $610{ }^{\circ} \mathrm{C}$ for 600 minutes, respectively. The main phases and precipitates observed in diffractograms are shown in Table 3. In this Table, the intensity of precipitation is categorized as high, middle or low. The results of X-ray diffraction revealed that the $\lambda$ phase $\left(\mathrm{Fe}_{2} \mathrm{Mo}\right)$, $\mathrm{Fe}_{3} \mathrm{Mo}, \mathrm{R}$ phase, and the carbides $\mathrm{MoC}, \mathrm{Fe}_{2} \mathrm{MoC}$ and $\mathrm{Fe}_{3} \mathrm{C}$ are intensely precipitated for the alloy containing $11 \%$ Mo submitted to the aging treatment. The diffractometry results confirm the results shown in Figures 2 and 3 obtained for the hardness and coercive force, respectively. 


\section{Conclusions}

The variation of hardness and magnetic properties of the Fe-xMo5Ni0.05C alloys ( $x=5,8,11$, and 15 wt. (\%)) were investigated. For all studied alloys, the amount of Mo increased both the magnetic and mechanical hardness. The Vickers hardness increases strongly after the 4 first hours of aging at $610^{\circ} \mathrm{C}$ and remains stable up to 10 hours for alloys containing $11 \%$ and $15 \%$ Mo. After this time, the Vickers hardness decreases slightly for the alloy containing $11 \%$ Mo. The coercive force $\left(\mathrm{H}_{\mathrm{c}}\right)$, during aging at $610{ }^{\circ} \mathrm{C}$ reaches a maximum value at 1 hour and thereafter remains constant. The Fe-15Mo-5Ni-0.05C alloy yielded a higher $\mathrm{H}_{\mathrm{c}}$ value after aging, due the higher content of Mo and consequently more precipitation, including a higher quantity of Laves phases. The alloys containing 11,8 and $5 \%$ showed reduction in mechanical hardness after 3 hours of aging.

\section{References}

1. Jin S and Tiefel TH. New ductile Fe-Mo-Ni magnet alloys. Journal of Applied Physics. 1981; 52(3): 2503-2505.

2. Abreu HFG, Braid A, Teodósio JR, Silva MR and Neto JM. Magnetic properties of Fe-Mo-5Ni-0.05C alloys with different contents of Molybdenum. Journal of Magnetism and Magnetic Materials. 1999; 185(1):107-111.

3. Bozorth RM. Ferromagnetism. Huntington: Robert Krieger Publishing Co.; 1978.

4. Wan H, Zhang YJ and Hadjipanayis GC. Magnetic hardening meltspun Fe-rich Fe-Mo alloys. Journal of Applied Physics. 1991; 69(8):5530-5532.
5. Myiazaki T, Takagishi S, Mori H and Kozakai T. The phase decomposition of iron-molybdenum binary alloys by spinodal mechanism. Acta Metallurgica. 1981; 28(8):1143-1153.

6. Sato S, Urushihara F and Suzuki T. Metastable miscilibity gap of Fe-Mo-Ni ternary alloys system, Nippon kinzoku Gakkaishi. 1992; 56(4):378-383.

7. Braid A, Abreu HFG, Teodósio JR, Neto JM and Silva MR. Studies on magnetic aged Fe-Mo-Ni-C alloys with different carbon additions. Journal of Magnetism and Magnetic Materials. 2001; 226(2):1425-1427.

8. Sykes AG. The Iron-Molybdenum System. Transactions AIME, Iron and Steel Division. 1938; 93(1):181

9. Souza MCL. Influência do teor de molibidênio e seus precipitados nas proprie-dades magnéticas das ligas Fe-xMo-5Ni-0,05C ( $x=5,8,11$ e $15 \%$ peso). [Tese de Doutorado]. Rio de Janeiro: Universidade Federal do Rio de Janeiro; 2001.

10. Souza MCL, Teodósio JR, Neto JM and Tavares SSM. Magnetic properties of Fe-xMo-5Ni-0.05C ( $\mathrm{x}=5,8,11$ and $15 \mathrm{wt} \%)$. Journal of Alloys and Compounds. 2002; 346(1-2):272-275.

11. Sato S, Urushihara F and Suzuki T. Effect of nickel addition on the phase decomposition of iron-molybdenum alloys. Scripta Metallurgica. 1983; 17(12):1391-1394.

12. Tavares SSM, Moura MP and Teodósio JR. Microstructural features of Fe-20Mo-5Ni-0.12C, magnetic alloys. Scripta Metallurgica et Materialia. 1995; 33(2):251-257.

13. ASM Handbook Committee. Alloy Phase Diagrams. Ohio: ASM International; 1997. p. 3-30.(vol. 3).

14. Abreu HFG, Teodósio JR, Neto JM and Silva MR. The influence of molybdenum on texture and magnetic anisotropy of semi-hard Fe-Mo5Ni-0.05C. Textures and Microstructures. 1999; 31(1):231-238. 